\title{
Left ventricular thrombectomy in the early postinfarction period
}

\author{
Aram Smolinsky, Zvi Ziskind, Rephael Mohr, Daniel A Goor, Michael Motro
}

\begin{abstract}
Emergency left ventricular thrombectomy was performed on four patients soon after infarction. In three patients surgery was carried out after embolisation had occurred and when a large, residual, protruding, mobile thrombus remained in the left ventricle. Surgery was performed in the fourth patient after a high risk thrombus was detected and initial attempts to lyse it had failed. All four patients had an uneventful recovery and were discharged within two weeks of surgery. These cases indicate that the therapeutic option of left ventricular thrombectomy is feasible for patients with acute infarcts and problematic left ventricular thrombi.
\end{abstract}

The incidence of left ventricular thrombosis in the three months after acute anterior wall myocardial infarction has ranged from $25 \%$ to $40 \%,{ }^{1-8}$ and has been even higher in pathological series. ${ }^{9}$ It is customary to distinguish patients with left ventricular thrombi developing shortly after acute myocardial infarction from those who are found to have a thrombus in a left ventricular aneurysm three months or more after the acute infarct. ${ }^{8}$ The structure of thrombi formed within the first few days of infarction differs from the well organised laminated thrombi that form within an aneurysm, although the former may evolve into the latter. Acute thrombi may be more friable and protrude further into the ventricular cavity and may therefore be more likely to embolise. ${ }^{8}$

Although most left ventricular thrombi do not cause clinical problems and resolve spontaneously even without anticoagulation, the incidence of systemic embolisation among patients with documented left ventricular thrombi may be as high as $35 \% \%^{3461011}$ Echocardiography has been used in the attempt to identify the thrombi that are particularly likely to embolise. ${ }^{11-16}$

Patients at high risk of embolisation from a left ventricular thrombus are those with recent acute myocardial infarction who have previously had emboli despite full anticoagulation. Finding an intracavitary protruding mobile left ventricular thrombus on a two dimensional echocardiogram may be a difficult management problem.

Meltzer et $a l^{8}$ defined emergency left ventricular thrombectomy as experimental surgery, and doubted its efficacy in preventing the development of further emboli; other workers have favoured this approach. ${ }^{17-19} \mathrm{We}$ report four patients who underwent emergency left ventricular thrombectomy soon after infarction, three after documented acute myocardial infarction and one after coronary bypass surgery with a probable subendocardial apical infarct.

\section{Surgical procedure}

Midsternotomy and cannulation of the ascending aorta, with a two stage atrial cannula for venous return, were used for normothermic cardiopulmonary bypass with no myocardial ischaemia (no aortic clamp). Left ventricular venting was done through the right upper pulmonary vein. The left ventricle was entered through the infarct, and the thrombi were carefully and meticulously removed. Closure of the ventriculotomy was strengthened with two Teflon felt strips. The area on and around the incision was then smeared with biological glue (GelatinResorcin Formol) and covered with a generous pericardial patch while the patient was on the cardiopulmonary bypass with strong left ventricular venting to facilitate a dry field. The margins of the pericardium were sewn to the surrounding epicardium with a running 4-0 prolene stitch. This technique provided a completely dry closure of the very friable, acutely infarcted muscle on the edges of the ventriculotomy, and was used in all four cases.

\section{Case reports}

CASE 1

A 53 year old man had a cerebrovascular accident with left hemiplegia and dysphasia four days after an acute extensive anterior myocardial infarction. Anticoagulation was given with intravenous heparin (for five days, to achieve a partial thromboplastin time of twice the normal) and warfarin by gastric tube was started at the same time (dosage adjusted according to the prothrombin time to achieve an international normalised ratio of $2 \cdot 5-3$ ). Nevertheless, six and 12 days later the patient required left and right femoral artery embolectomy respectively for peripheral emboli. Echocardiography performed after the first embolectomy showed akinesis of the anterior wall, good contraction of the posterolateral and inferior walls, and a large and mobile protruding left ventricular thrombus. After the second embolectomy the left ventricular thrombus was shown by echocardiography to 
be smaller but it was still quite large and mobile and protruded into the cavity.

Six days later (three weeks after the acute myocardial infarction) the left ventricular thrombus was removed as described above. The left ventricular cavity was approached via an apical incision and a $4 \mathrm{~cm} \times 3 \mathrm{~cm}$ fresh, red, mobile and friable left ventricular thrombus, attached to the free apical wall, was removed. The postoperative course was uneventful. The patient was discharged in excellent condition, with normal intellectual function and minimal residual left hemiparesis. Echocardiography four months after operation showed no intracardiac thrombus.

\section{CASE 2}

A 63 year old man underwent urgent coronary bypass surgery because of acute ischaemia. $\mathrm{He}$ had no history of myocardial infarction, left ventricular contractility was normal, and there was no echocardiographic evidence of an intracardiac mass. The operation included a saphenous vein graft to the left anterior descending and right coronary arteries, and a left internal mammary artery graft to the major diagonal artery. The left ventricle was vented via the right upper pulmonary vein. Four days after surgery the patient developed intractable hiccups. Two days later he developed hemiplegia, and 48 hours later he was stuporous.

Computed tomography showed multiple infarctions in the right cerebral hemisphere, infarction of the right upper nephric pole, and infarction of the spleen. Echocardiography showed a protruding mobile thrombus in the left ventricle with normal left ventricular function. We assumed that the patient had had a small apical subendocardial infarct, on which the thrombus had formed. Thrombolysis was contraindicated by his recent surgery and a history of peptic disease was a relative contraindication to warfarin. The left ventricle was entered through the apex, and a $1.5 \times 2 \mathrm{~cm}^{3}$ white thrombus was excised. There was no evidence of an old or new infarct. His postoperative course was uneventful. $\mathrm{He}$ was discharged with residual leg paresis but no residual left ventricular thrombus on his postoperative echocardiogram.

\section{CASE 3}

A 61 year old previously healthy woman was admitted elsewhere with chest pain, a slight rise in myocardial enzymes, and S-T segment changes in the anterior chest leads, suggesting a subendocardial anterior myocardial infarction. She had an uncomplicated stay in hospital and was discharged after eight days. She was admitted to our hospital two weeks later with an acute arterial occlusion of the right leg, and a right femoral embolectomy was performed. She received intravenous heparin before the operation and aspirin thereafter.

Echocardiography performed the next day disclosed good left ventricular function and a large, highly mobile protruding left ventricular thrombus. Coronary angiography showed distal occlusion of the left anterior descending artery. Thrombectomy was performed. A fresh, mobile, and friable thrombus measuring $2 \times 4 \mathrm{~cm}$, located on a small apical scar, was removed. The operative and the postoperative course was uneventful. The patient was discharged on the 10 th postoperative day.

\section{CASE 4}

A 54 year old woman was admitted with severe precordial pain; an evolving anterior myocardial infarction was diagnosed and thrombolytic treatment with $r$ tissue plasminogen activator was performed. Intravenous heparin was started immediately after the $r$ tissue plasminogen activator, the dosage being adjusted to maintain the partial thromboplastin time at 60 seconds. Aspirin $500 \mathrm{mg}$ a day was also started on the first day. Good clinical and electrocardiographic criteria for reperfusion were evident. No left ventricular thrombus was seen on a routine echocardiogram. Heparin was stopped after three days. Cardiac catheterisation, performed five days later as part of the thrombolysis protocol, showed a severe proximal left anterior descending lesion; it was dilated with percutaneous transluminal coronary angioplasty. Because of persistent pain a second catheterisation was performed the next day. The patency of the left anterior descending artery was confirmed but ventriculography suggested a left ventricular thrombus. Repeat echocardiography showed a big, round, protruding thrombus in the left ventricular cavity (fig 1). The patient had had no emboli. Emergency thrombectomy was

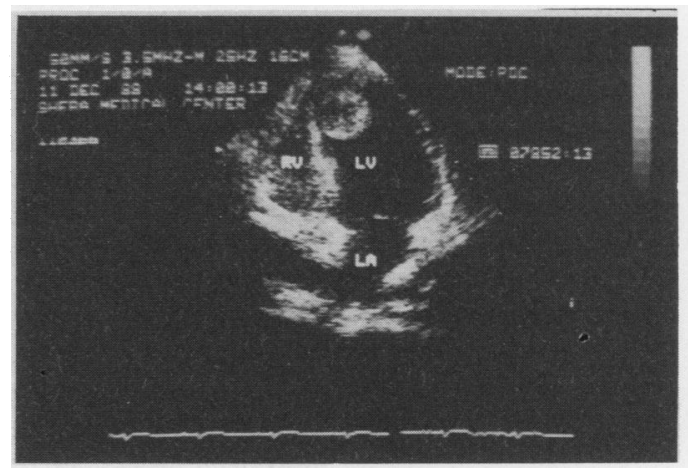

Figure 1 Case 4: Apical chamber view eight days after acute anterior wall myocardial infarction. An intracavitary round mobile mass is evident. $R V$-right ventricle; $L V$-left ventricle; $L A$-left atrium. The thrombus is indicated by an arrow.

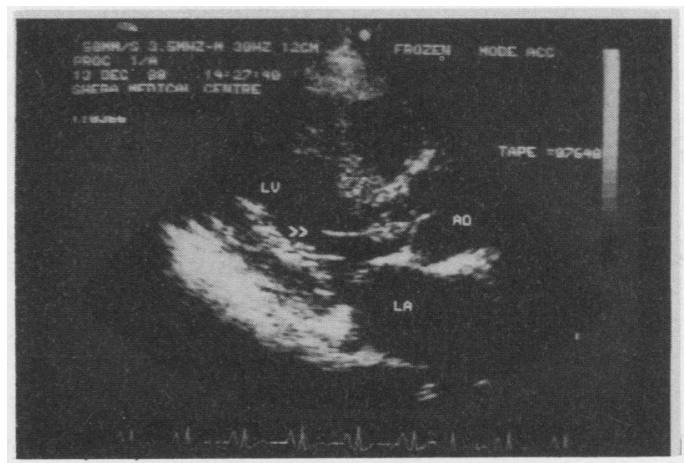

Figure 2 Long parasternal view 10 days after myocardial infarction (two days after fig 1). A new mass is located under the aortic valve attached to the mitral apparatus, with a long chord (two arrowheads). LVleft ventricle; $L A$-left atrium; $A O$-aorta. 
Figure 3 Ten days after emergency surgery in case 4: apical four chamber view; the left ventricular lumen is clear of thrombi. $L V$-left ventricle; $R A-$ right atrium; $L A$-left atrium.

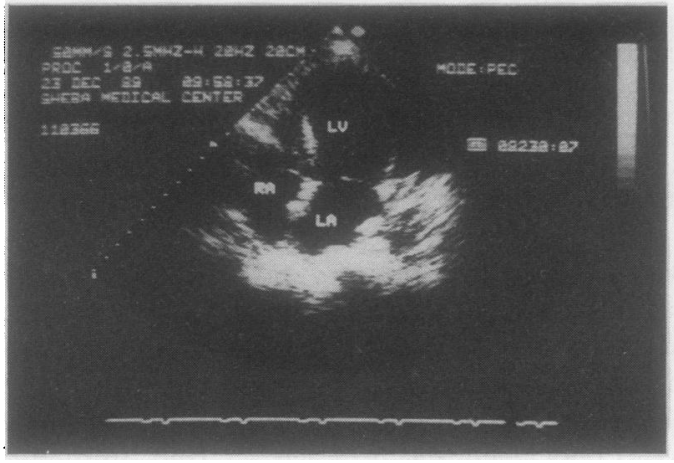

contemplated but we decided in favour of further anticoagulation with intravenous heparin. Two days later, while she was receiving heparin by infusion (25000 units/ day) and had a partial thromboplastin time of around 60 seconds, the echocardiographic study was repeated. The large apical thrombus had not changed in shape but a new thrombus had appeared; it was attached to the chordae of the anterior mitral leaflet just below the aortic valve and had a long chord (fig 2). Emergency surgery was decided upon. The patient underwent uneventful left ventricular thrombectomy with construction of a single coronary artery bypass graft. Echocardiography prior to discharge showed no left ventricular thrombus (fig 3).

\section{Discussion}

The occurrence of a stroke after acute myocardial infarction resulting from an embolus from a left ventricular thrombus is a devastating complication for the patient, and a source of frustration for the attending physician. Emergency left ventricular thrombectomy carries all the risks of surgery for a patient with acute myocardial infarction with the added problem of closing the friable ventriculotomy. Follow up studies have not determined whether or not the thrombosis and embolism will recur after the operation. In a review of this issue Meltzer et al ${ }^{8}$ opposed an operative approach to this problem, calling it "experimental surgery."

Anticoagulation in patients with acute myocardial infarction and left ventricular thrombosis has been unsatisfactory in our experience and that of others $\mathrm{s}^{20-23}$; this is illustrated by case 4 of this series. In our first three cases surgery was used after emboli had occurred in an attempt to prevent further emboli. In the fourth case it was performed prophylactically after anticoagulation had failed not only to lyse the ominous looking thrombus but also to prevent the development of a second thrombus.

All the patients underwent surgery at normal temperature, without myocardial ischaemia, only short periods of ventricular fibrillation being used. The customary ventriculotomy closure with Teflon felt strips was routinely reinforced with biological glue and a pericardial patch, facilitating smooth and haemostatic surgery. None of the patients needed the support of an intra-aortic balloon. All were discharged within two weeks of their operation. All thrombi had disappeared according to the two dimensional echo studies at follow up.

Our results and those of others ${ }^{14-16}$ show that left ventricular thrombectomy in the setting of acute myocardial infarction is a therapeutic option. The question of when precisely it is indicated, and whether it should ever be attempted before proof of failure of medical treatment has been obtained, is hard to answer. A surgeon faced with an ominous echocardiographic picture of a protruding, mobile intracavitary thrombus in the left ventricle knows that medical treatment may fail and the patient may have a stroke. The risk of fragmentation of the thrombus by thrombolysis is not negligible. Surgery in the early postinfarction period carries additional risks, however, because of poor left ventricular performance, arrhythmias, and the friable left ventricular myocardium, and these problems can be difficult to manage. Proper double blind prospective studies have not been carried out but should be considered, in the hope of resolving this dilemma. Meanwhile this report lends support to those who claim that surgical removal of left ventricular intracavitary protruding thrombi soon after infarction is an acceptable therapeutic option when medical treatment has failed.

1 Asinger RW, Mikell FL, Elsperger J, Hodges $M$. Incidence of left ventricular thrombosis after acute transmural myocardial infarction. N Engl J Med 1981;306:297-302.

2 Johannessen KA, Nordrehaug JE, von der Lippe G. Lef ventricular thrombosis and cerebral vascular accident. $B r$ Heart $J$ 1984;51:553-6.

3 Visser CA, Kan G, Lie KI, Durrei DD. Left ventricular thrombosis following acute myocardial infarction: Prospective serial echocardiographic study of 96 patients. Eur Heart J 1983;4:333-7.

4 Friedman MJ, Carlson K, Marcus FI, et al. Clinical correlation in patients with acute myocardial infarction and left ventricular thrombus detected by twoand left ventricular throm. Am JMed 1982;72:894-8.

5 Wienreich DJ, Bruke JF, Pauletto FJ. Left ventricular mural thrombi complicating acute myocardial infarction. $A n n$ Intern Med 1984;100:789-94

6 Keating EC, Gross SA, Schlamowitz RA, et al. Mural thrombi in myocardial infarction. Am J Med 1983;74: 985-95.

7 Benichou M, Aubry J, Larbi MB. Detection of left ventricular thrombi in acute phase of myocardial infarction by two-dimensional echocardiography: A series of 103 cases. Arch Mal Coeur 1983;76:1012-9.

8 Meltzer RS, Visser AC, Fuster V. Intracardiac thrombi and systemic embolization. Ann Intern Med 1986;104:689-98.

9 Hellerstein HK, Martin JW. Incidence of thrombo-embolic lesion accompanying myocardial infarction. Am Heart $J$ lesion accompanying
1946;32:443-52.

10 Tramarin R, Pozzoli M, Febo O, Opasich C, Cobelli F, Specchia G. Echocardiographic assessment of efficacy in left ventricular thrombosis post myocardial infarction [abstract]. Circulation 1983;68(suppl 3):331.

11 McEntee CW, Van Reet RE, Winters WL, et al. Incidence and natural history of mural thrombi in acute myocardial infarction by two dimensional echocardiography [abstract]. Circulation 1981;64(suppl 4):93.

12 Haughand JM, Asinger RW, Mikell FL, et al. Embolic potential of left ventricular thrombus detected by twodimensional echocardiography. Circulation 1984;70 588-98.

13 Meltzer RS, Visser CA, Kan G, et al. Two-dimensional echocardiographic appearance of left ventricular thrombi with systemic emboli after myocardial infarction. $A m$ Cardiol 1984;53:1511-3.

14 Visser CA, Kan G, Meltzer RS, et al. Embolic potential of left ventricular thrombus after myocardial infarction: twodimensional echocardiographic study of 119 patients. J Am Coll Cardiol 1985;5:1276-80.

15 DeMaria AN, Bommer W, Neumann A. Left ventricular thrombi identified by cross-sectional echocardiography. thrombi identified by cross-secti

16 Johannessen KA. Peripheral emboli from left ventricular thrombi of different echocardiographic appearance in 
acute myocardial infarction. Arch Intern Med 1987;147:641-4.

17 Fournial G, Clock Y, Berthoumieu F, Allibelli MJ, Desrez $\mathrm{X}$, Marco J. Thrombus flottant du ventricule goude apres infarctus du myocarde recent traite chirurgicalment. Arch Mal Coeur 1980;12:1415-20.

18 Nilli M, Deviri E, Jortner R, Strasberg B, Levy MJ. Surgical removal of mobile pedunculated left ventricular thrombus: Report of 4 cases. Ann Thorac Surg 1988;46: 396-400.

19 Lew AS, Federman J, Harper RW, et al. Operative remova of mobile pedunculated left ventricular thrombi detected by 2-dimensional echocardiography. Am J Cardiol 1983:52:1148-9.
20 Arvan S, Plehn J. Embolization of a left ventricular mural thrombus: verification by two-dimensional echocardiography. Arch Intern Med 1982;142:1952-3.

21 Howang MH, Pacold J, Loeb HA. Acute anterior myocardial infarction complicated by mural thrombus and peripheral thromboembolism despite anticoagulation. peripheral thromboembolism despite antic

22 Arvan S. Persistent intracardiac thrombi and systemic embolization despite anticoagulant therapy. Am Heart $J$ 1985;109:178-81

23 Arvan S, Boscha $K$. Prophylactic anticoagulation for left ventricular thrombi after acute myocardial infarction: a prospective randomized study. Am Heart $J$ 1986;133: 688-93. 